\title{
Using the AREA Approach to Create Successful Writers
}

\author{
William M. Yerger \\ Loeb School of Education, Eastern University, St. Davids, USA \\ Email: wyerger@eastern.edu
}

Received August 22 ${ }^{\text {nd }}, 2012$; revised September 20 $0^{\text {th }}, 2012$; accepted October $5^{\text {th }}, 2012$

\begin{abstract}
The high stakes assessments that states are now administering use a rubric where not only is a correct response required by students, but also a justification or rationale for that response is needed for a higher score on the item. The AREA approach discussed in this article is an excellent strategy that both students and teachers can successfully employ in answering questions either in writing or in public speaking. It is a clear, straightforward way of responding to a question with assurance that the response was developed in a thorough and organized manner.
\end{abstract}

Keywords: Instructional Strategies; Methods and Materials; Methodological Perspectives; Motivation/Engagement; Writing Approaches

\section{Introduction}

Students are required daily to answer numerous questions in class, on tests, and in everyday life. The high stakes assessments that states are now administering use a rubric where not only is a correct response required, but also a justification or rationale for that response is needed for a higher score on the item. The rationale that students give must be thorough and complete. Students no longer can just guess and get the full credit if they are correct. Many schools are now offering specific prep courses that students are required to take if they are not proficient in a given subject matter. These courses are designed to take students through a rigorous curriculum that will stretch critical thinking and ability all for the purpose of preparing students for state assessments.

\section{Writing Approaches}

The author has found and utilized numerous approaches to writing that students can use to improve their products in persuasive, informational, and entertaining (PIE) writing. Three approaches that are noteworthy include the RAFT (Buehl, 2008; Holston \& Santa, 1985), GIST (Cunningham, 1982) and the AREA approach (Mamchak \& Mamchak, 1991).

The RAFT is an exciting creative writing approach which allows the writer the flexibility to deal with persuading, informing, or entertaining. The acronym of RAFT stands for:

Role of the Writer

Audience that is being addressed

Format of the writing, i.e. letter, article, speech

Topic being addressed

An example (Frank, Grossi, \& Stanfield, 2006) of this could be as follows from a social studies class:

Role: Colonist

Audience: King of England

Format: Letter

Topic: Unfair taxation

Tompkins (2013) shares teaching procedures and examples of the RAFT technique along with how to differentiate instruction with tiered techniques and projects.
The second approach GIST is a useful technique for summarizing and getting the main idea in any subject.

Students work in pairs to develop a 20-word summary of the material read or discussed. This technique focuses the students' attention and thinking in a reflective manner.

The third approach I found a few years ago for developing support for the answer was not found in any writing book. It was found in a book on public speaking (Mamchak \& Mamchak, 1991). Upon reflecting on the approach, it's the same one that Ronald Reagan, the great communicator, used in answering questions for the press. The approach is entitled the AREA approach. I will elaborate on this one extensively because of its simplicity of application and demonstrated improvement of test results when this approach is taught to teachers and utilized by students.

Very simply stated, when someone asks a question the one answering the question needs "to cover the area well" to convince others of their response. This means to be as thorough as possible in the response, covering the information fully. Your approach should reflect a positive attitude, passionate response, and an optimistic viewpoint.

\section{AREA Components}

Specifically, the AREA approach to answering a question is as follows:

Answer the question in a simple sentence;

Reason(s) stated for the answer;

Example(s) shared supporting the reason;

Answer Again.

In using this approach with students, I no longer find that they do not know what to write about or what to say. Once they take a position they just need to follow the formula in a prescribed step-by-step manner. Fear leads to writers block. Students face the fear of not knowing if they are good enough, if anyone will like it, if they can finish, if they can start. However, the AREA approach takes the fear out of writing for many students. For others it serves as a check on their position, developing added confidence in their response. 


\section{AREA Approach Example 1}

An example that could be utilized follows:

- Should students be allowed to wear hats in class?

Answer:

I feel that students should not be allowed to wear hats in class.

\section{Reason:}

It can pose problems for other students and even themselves.

Example:

If the hat is novel, others may be looking at it and not paying attention to the teacher. If it's a large hat, it may block the vision of others. The one wearing it may also be distracted by moving it around on his head.

Answer Again: Therefore, I feel that hats should not be worn in class because of the distraction created and the lost focus on learning.

A counter example of responding to the question without clarity might sound like:

"No, they shouldn't" or "No, it's not a good idea for kids to wear hats in school. Hats are for outside the classroom." A response like this lacks clarity and specificity, doing little to persuade or convince anyone to accept their thinking. It just is an unsupported opinion rather than based on real facts.

Once students see the example they are ready to develop a group response to a question using the AREA approach. The following are possible questions, listed by designated levels to be used with students:

Grades 3-5:

- Should recess (including at lunch time) be eliminated in schools?

Grades 6-8:

- Who do you think was our greatest American hero?

Grades 9-12:

- Should students be paid for coming to school?

\section{AREA Approach Example 2}

The teacher writes AREA vertically on the board, chart paper, etc. and has the students assist in the development of the response. The position that the students take does not matter. What does matter is the support for the position. For example, two different responses are addressed below to the question:

- Grades 3-5: Should recess be eliminated from schools?

In defense of recess:

Answer

We believe that recess should not be eliminated from schools.

Reason(s)

Students in the same environment need the opportunity to move during day.

One cannot operate at his/her best without having the chance to stretch. Many children are in poor physical shape and need to get appropriate exercise.

\section{Example(s)}

Brain fatigue will cause the mind to disconnect from the learning after too long a sustained period of time as seen when students yawn or become fidgety. When students get a chance to run and move, their brain recovers from the sameness syndrome that can hamper learning. Finally, the schools need to model for students life-long leisure activities and the importance of exercise to keep students from becoming couch potatoes. Students today spend less time outdoors. The 21st Century has seen huge advancements in technology. Video games have become a huge business targeting the youth of today. The expansion of this market has created an environment where students are spending the majority of their time indoors.

The 3 R's? A fourth is crucial, too: Recess. New research suggests that play and down time may be as important to a child's academic experience as reading, science and math, and that regular recess, fitness or nature time can influence behavior, concentration and even grades. A study published in the Journal of Pediatrics studied the links between recess and classroom behavior among about 11,000 children aged 8 and 9. Those who had more than 15 minutes of recess a day showed better behavior in class than those who had little or none (Parker-Pope, 2009).

\section{Answer Again}

Recess should not be eliminated from the elementary school as it is a benefit to learning and the development of life-long positive exercise habits.

In opposition to recess:

\section{Answer}

We believe that recess should be eliminated from schools.

Reason(s)

Teachers will tell you that the most problems that they deal occur at recess and instructional time is wasted.

\section{Example(s)}

Students fight, don't get picked for teams, are bullied, fall and get hurt, just to name a few. Then, students' learning is affected as solving these problems too often spills over into the classroom where the teacher is not able to begin the lesson on time.

\section{Answer Again}

Recess needs to be eliminated as the problems caused create hard feeling and detract from instructional time.

After the teacher develops the response through a shared writing with the students, the children can do guided practice in a small group or with a buddy before each student one alone.

\section{AREA Approach Example 3}

Below are two additional examples of AREA best practices in use.

- Grade 6-8: Who do you think was our greatest American hero?

\section{Answer}

I feel that George Washington was our greatest American hero. Reason(s)

George Washington helped found our countries values, beliefs, and government. He was America's very first President and is known as the "Father of our Country". He was a distinguished general and commander in chief of the colonial armies in the American Revolution.

\section{Example(s)}

You might have thought that George Washington was in Philadelphia with Thomas Jefferson, Benjamin Franklin, John Adams and the other delegates of the Continental Congress as they wrote the Declaration of Independence, but he wasn't. In July 1776, Washington was in New York with his troops. On July 9th, he received his copy of the Declaration with a note from John Hancock telling Washington to share the news with the troops. After the war was over, Washington hoped he would be able to retire and return to Mount Vernon. Instead, in 1789, the electors unanimously voted George Washington the first 
president of the United States. Because it was such an honor, and he felt a great duty to his country, he accepted. He left Mount Vernon on April 16 and arrived in New York City on April 30 for his inauguration. As he took his oath standing on the balcony of Federal Hall, a crowd broke into cheers. The members of his first Cabinet included Thomas Jefferson as secretary of state, Alexander Hamilton as secretary of the treasury, Henry Knox as secretary of war, and Edmund Randolph as attorney general (The Library of Congress, 2013).

\section{Answer Again}

Due to George Washington's amazing leadership and people skills, he was respected by an entire country. His dedication to America was what propelled him to the position of being the first President of the United States.

\section{AREA Approach Example 4}

Grade 9-12: Should students be paid for coming to school? Answer

I do not feel that students should be paid for attending school.

\section{Reason(s)}

Students should not be paid because it is a privilege to attend school and payment would cheapen that privilege. Students are currently obligated to attend school and should they stop attending they become truant.

\section{Example(s)}

In today's world so many students already feel they are "entitled" to certain liberties while at school. Many students are disrespectful and talk back to the educators. If we begin compensating the students monetarily, we will have multiple issues to deal with; such as how much payment is to be given, how do we keep payment fair across the country, and who would be responsible to pay the money?

\section{Answer Again}

Therefore, I do not feel students should be paid for attending school because it is a privilege to attend school, and each student is offered a free and appropriate education in the United States.

\section{Additional Questions}

Depending on the grade level, some high interest questions are listed:

- Should teachers be allowed to take cell phones from students?

- Should students have to pay to participate in sports?

- Is it reasonable for students to have a curfew?

- Should students be allowed to wear to school?

- Should students be permitted to chew gum?

- Is it a privilege for students to drive to school?

- Should students be allowed to pick their teachers for classes?

- Should students be allowed to have privileges in school based on their grades?

The above examples are not related to the curriculum, but develop the interest, skills, and success needed for responding to the same type of questions in the curriculum. The following are some curriculum related questions:

- How would the United States be different today if Columbus had landed in San Francisco Harbor instead of the East Coast?
- Through which medium does sound travel the greatest distance?

- How did you come up with 18 feet for the perimeter?

- Why do you think that the character responded in that manner?

- How is the book “Animal Farm” by George Orwell, related to the Russian Revolution of 1917?

- How does the human "five senses" affect an individual's personal and mental health?

- How many years did it take to build the Great Wall of China?

\section{Application}

I've found that in using this approach with students and teachers one way to help them think and organize their thoughts is to tell them the following:

"If you wanted to find out something about the topic on the internet, what would some key words that you could put in a search engine that would assist you in finding information about the topic? Also, what do you already know about some of the key words?"

One time I was presenting the AREA approach to teachers in a school district near the Atlantic seacoast.

In order to demonstrate the effectiveness of the approach I shared the following: "Now that I've given you an example of the approach, I'd like someone to give me any question in the world that you would like me to respond to. If the question is too technical, I'll tell you. Otherwise, I'll answer it using the AREA approach.”

The room was silent for about ten seconds, after which one of the teachers in the group put me to the test with this question:

- What should a person do if they experience a decompression injury while scuba diving?

Well, I have never scuba dived and wondered if I was really going beyond my headlights in answering the question. I did what is prescribed in the Mamchak book mentioned earlier: "Repeat the question for everyone to hear." This is actually done to give the speaker more reflection time in dealing with the question so they can better organize their thinking. Immediately what went through my mind was both the key search engine words and what did I already know about some of the words expressed in the question. The words that came onto my radar screen were scuba diving, decompression, and injury. Since I knew very little about the first two words, I focused on the third word, injury.

Here's the question repeated and how the response sounded:

- What should a person do if they experience a decompression injury while scuba diving?

\section{Answer}

Short of going to a doctor or medical facility and receiving help, a person who has experienced a decompression injury while scuba diving needs to stay out of that situation for six to eight weeks.

\section{Reason(s)}

We know that when the body has experienced nearly any kind of severe blow, trauma, or injury, it takes about six to eight weeks for the body to heal. Bones, tissues, and corpuscles need time to be restored.

\section{Example(s)}

If a person experiences a broken arm or leg, the doctor generally 
Table 1.

ESPA tests in grade 5.

\begin{tabular}{|c|c|c|c|c|}
\hline & Partially Proficient & Proficient & Advanced Proficient & \\
\hline Language Arts Literacy & $15.7 \%$ & $80.4 \%$ & $3.9 \%$ & Year 1: Before AREA Introduced \\
\hline Language Arts Literacy & $10.5 \%$ & $73.7 \%$ & $15.8 \%$ & Year 2: After One Year of AREA Approach \\
\hline Language Arts Literacy & $0.0 \%$ & $73.0 \%$ & $27.0 \%$ & Year 3: After Two Years of the AREA Approach \\
\hline
\end{tabular}

Results attained by the New Jersey statewide testing system over three consecutive years.

tells you that it will take at least six weeks and as many as eight weeks till you're fully healed. The same is true for the healing time for a mother after childbirth. Major operations also take about the same amount of time.

Answer Again

Therefore, because of the trauma to the body and healing needed, short of going to a doctor or medical facility and receiving help, a person who has experienced a decompression injury while scuba diving needs to stay out of that situation for six to eight weeks. After I finished answering the question, I asked her how I did. To my delight she surprisingly stated, “That's exactly right!”

I have shared this technique over the last fifteen years with teachers coming back to me telling how well students are now answering questions along with getting better results on the statewide tests. My own daughter while in college took the Praxis 1 Writing Test and scored twelve points out of thirteen on the section where they had to answer a question and justify what they wrote. She told me, "Dad, I wrote the word AREA and did what you and mom taught me about the approach." She shared the question and what she said in answering the question. I didn't even agree with what she wrote, but she provided the reasons and examples for her thinking which gave her the good score.

\section{Research on Classroom Application}

When I was an elementary principal I decided to not only in-service the intermediate teachers on the

AREA approach but also to follow the test results. I met with them one morning, bringing in a fluorescent poster board with the AREA approach on it. After teaching them the method and giving examples, they taught it to their students complete with a chart similar to the one that I brought in. They posted the chart in the room and had children write responses in class following the procedure. The results that we achieved on the New Jersey ESPA Language Arts Literacy Test were remarkable. Our school went from one of the lowest in the school district to one of the highest in the state. The number of students who became advanced proficient increased nearly seven times after using the approach for two years.

Poster of the AREA Chart

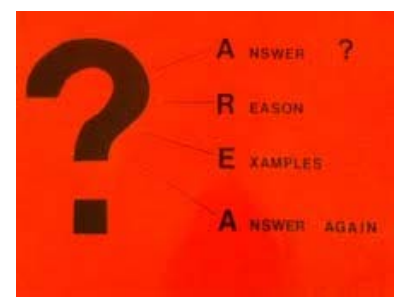

Table 1 shows the outcome.

\section{Final Example}

Presently, I teach the method to my undergraduate students. They find it very easy to write a paper on "My Most Effective Teachers” just to name one. I also continue to in-service teachers as a consultant to school districts. In addition, I have personally found the AREA approach an effective and successful tool in preparing aspiring teachers for an interview. For example, a potential teacher may be asked, "What do you feel are your greatest strengths that you would bring to this job?" By using the AREA approach the interviewee will most certainly be convincing if not remarkable.

\section{Conclusion}

In summary, the AREA approach is the best strategy that I have ever used with students and teachers in answering questions. It is a clear, straightforward way of answering a question with assurance that you've responded in a thorough and organized manner. Its components of Answer the question, Reasons for your response, Examples to support the reasons, and Answer again to emphasize and summarize the main points clearly are easy to follow for the presenter and creates a clear understanding for the recipient.

\section{Acknowledgements}

Special acknowledgement goes to Paul Dunn, my graduate assistant who added some ideas and reviewed the work.

\section{REFERENCES}

Buehl, D. (2008). Classroom strategies for interactive learning (3rd ed.). Newark, DE: International Reading Association.

Cunningham, J. W. (1982). Generating interactions between schemata and text. In J. A. Niles \& L. A. Harris (Eds.), New inquiries in reading research instruction (pp. 42-47). Rochester, NY: National Reading Conference.

Frank, C., Grossi, J., \& Stanfield, D. (2006). Application of reading strategies within the classroom: Explanations, models, and teacher templates for content areas in grades 3-12. New York: Pearson Education, Inc.

Holston, V., \& Santa, C. (1985). Raft: A method of writing across the curriculum that works. Journal of Reading, 28, 456-457.

Mamchak, P., \& Mamchak, S. (1991). School administrator's public speaking portfolio. West Nyack, NY: Parker Publishing Company.

Parker-Pope, T. (2009). The 3 R's? A fourth is crucial, too: Recess. URL (last checked 23 February 2009). http://www.nytimes.com/2009/02/24/health/24well.html

The Library of Congress, George Washington (2013). URL (last checked 16 October 2012).

http://www.americaslibrary.gov/aa/wash/aa_wash_subj.html

Tompkins, G. (2013). 50 literacy strategies: Step by step (4th ed.). New York: Pearson Education, Inc. 